AperTO - Archivio Istituzionale Open Access dell'Università di Torino

Life cycle assessment as a tool to integrate environmental indicators in food products: A chocolate Ica case study

This is a pre print version of the following article:

Original Citation:

Availability:

This version is available http://hdl.handle.net/2318/1607343

since 2016-10-24T15:03:09Z

Published version:

DOI:10.1504/IJENVH.2016.077660

Terms of use:

Open Access

Anyone can freely access the full text of works made available as "Open Access". Works made available under a Creative Commons license can be used according to the terms and conditions of said license. Use of all other works requires consent of the right holder (author or publisher) if not exempted from copyright protection by the applicable law. 


\title{
Life Cycle Assessment as a tool to integrate environmental indicators in food products: A chocolate LCA case study
}

\author{
Enrica Vesce ${ }^{1 *}$, Germana Olivieri $^{2}$, Maria Beatrice Pairotti ${ }^{3}$, Annalisa Romani ${ }^{4}$ and \\ Riccardo Beltramo 5 \\ 1 Dipartimento di Management, Università degli Studi di Torino, Corso Unione Sovietica 218 bis, \\ 10134 Torino E-Mail: enrica.vesce@ unito.it; \\ 2 LCA - lab s.r.l., presso ENEA, Agenzia nazionale per le nuove tecnologie, l'energia e lo sviluppo \\ economico sostenibile, Bologna. E-mail:germana.olivieri@enea.it \\ 3 Dipartimento di Management, Università degli Studi di Torino, Corso Unione Sovietica 218 bis, \\ 10134 Torino E-Mail: mariabeatrice.pairotti@unito.it; \\ 4 Dipartimento di Statistica, Informatica, Applicazioni 'G. Parenti' (DiSIA), Università di Firenze,E- \\ Mail: annalisa.romani@unifi.it \\ 5 Dipartimento di Management, Università degli Studi di Torino, Corso Unione Sovietica 218 bis, \\ 10134 Torino E-Mail: riccardo.beltramo@unito.it; \\ * Author to whom correspondence should be addressed; E-Mail: enrica.vesce@unito.it; \\ Tel.: +39-011-6705711; Fax: +39-011-6705720
}

\section{Biographical notes}

Enrica Vesce is Associate professor at the School of Management and Economics, University of Turin, Department of Management, Commodity science area. Her research interests are about ecolabelling of products and services, instruments and models for environmental analysis, industrial Ecology, Equipped Ecologically Industrial Areas. Current teaching: Operations management and Environmental technology (School of Management and Economics, University of Torino); Commodity Science, in integrated course of Chemistry and Food Science (School of Medicine, University of Torino).

She took part in many projects with private and public institutions.

Germana Olivieri is co-founder and Executive Manager of LCA-lab srl, an environmental consulting and research company specialized in Life Cycle Assessment, Carbon Footprint studies and Environmental Product Declarations (EPD), spin-off ENEA, the Italian National Agency for New Technologies, Energy and Sustainable Economic Development. Ph. D in Commodity Science, she is 
working in the field of SMEs Environmental Management and Eco-design since 2002. Teaching experience in University Course and Master.

Maria Beatrice Pairotti is Ph.D in Commodity Science, with a thesis about the evaluation of environmental sustainability of foods productions. Now, she is Research assistant at the School of Management and Economics, University of Turin and she collaborates on many projects in the Commodity science area. Her researches and studies cover different fields, about environment, energy, transports and tourism. Her teaching activities at the University concern operations management, energy sources, waste, environmental sustainability.

Annalisa Romani is Researcher since 1996 and Associate Professor of Chemistry and Commodity Science since 1999. Her research activity is carried out in the Department of Pharmaceutical Sciences of the University of Florence. She is an instructor of Chemistry and Commodity Science and Quality Control in various degrees University Course and Master. She is Scientific Referent of Laboratory of Commodity Control and Assurance of the Product, PIN, Prato (Italy), University of Florence. Her research concerns the isolation, characterization and quali-quantitative evaluation of natural compounds present in vegetal matrices of interest in food and environmental analyses and for pharmaceutical and/or cosmetic applications. Many areas of interest have been developed in collaboration with both public and private research groups.

Riccardo Beltramo is Full professor of Operations Management at the School of Management and Economics, University of Turin. At the same University, he taught Industrial Ecology and Integrated Certification Systems; Environmental Management Systems and Certification; Environmental Technology. Coordinator of the area "Commodity Science", within the Department of Management, he is currently President of the on line Course in Business Administration and President of the Centre NatRisk, a network for the theoretical, experimental and applied research and dissemination in the field of forecasting, prevention and risk management of natural disasters in the mountains and hills.

His researches concern the environmentally sustainable use of resources and are held in very diverse areas, from sea to high mountains, in collaboration with different kind of economic and research organizations. 


\begin{abstract}
Environmental indicators help researchers to understand impacts and pollutions issues. There is a need for an indicator (index) that provides the right information to the decision-maker regarding possible improvements to food production systems and that is useful for making comparisons among companies, evaluating their ability to reduce environmental impacts. Among the research methodologies for establishing thresholds and assigning scores, the life-cycle assessment (LCA) approach was selected.

In order to test this approach, the LCA methodology was applied to a chocolate production case study in an Italian small- or medium-sized enterprise (SME) located in the Piedmont region. The aims of this analysis are: to use the LCA results as a starting point to identify the critical environmental and energy aspects of the 'gate-to-gate' life-cycle system; to evaluate the results, considered like scores to compare other local chocolate production; to assess the main limitations of the SME in terms of both the acquisition data and the application of the LCA methodology; and finally to understand how to include the threshold values in the environmental index using the LCA results. Adopting both mid-point and endpoint analysis, the LCA case study shows that the most significant environmental aspects are energy consumption, depletion of non-renewable resources, and climate change. Furthermore the transport of raw materials, the mixing, the conching, and the milling are the life-cycle phases that have the largest environmental impacts.
\end{abstract}

Some of the primary unavailable data for the life-cycle inventory phase and the need to adopt the same initial hypotheses to carry out comparative studies are the main limitations of the LCA application. The preliminary LCA results, such as energy or $\mathrm{CO}_{2}$ eq. indicators, could be good factors to be integrated in the environmental Index.

Key words Environmental indicator; sustainability; Life Cycle Assessment; environmental assessment methodologies 


\section{Introduction}

The use of indicators satisfies the necessity to understand and measure impacts and matters concerning pollution. Major environmental issues have grown in importance recently, and the need to establish concrete targets in order to move towards sustainable development has become more pressing. The scientific community has had to respond to a series of requests on this point (Beldřich et al., 2012; Ness et al., 2007), and the most frequently used tools for this purpose have included indicators that provide practical key measures (Herva et al., 2011; Huysman et al., 2015 and Ness et al., 2007).

Currently, the food sector is the most investigated sector with regard to the environmental sustainability of processes and products. From carbon footprints and other carbon labels, to the study of agronomic and production systems and Environmental Product Declarations (EPDs) (GEDnet, 2014), research and studies have focused on the impact of food production.

At a corporate level, indicators are used to either communicate environmental performance or to construct integrated or environmental labels, both public and private. In the latter case, indicators play a crucial role because labelling systems have to establish thresholds in order to allow firms to obtain labels for their products (Olsthoorn et al., 2001).

This paper presents tools that are able to build an environmental index of production designed to be part of a label for the food sector (Engels et al., 2010; Halberg et al., 2005 and Van der Werf et al., 2002) in accordance with current guidelines and market demands. The instruments identified have been analysed to choose the right tool to evaluate food production in terms of its environmental impacts and to measure its degree of sustainability (1).

The environmental analysis consists of agricultural, production, and packaging phases; the three parts are then synthesised with different weights in the index. The biggest challenge faced by this study was to attribute a relative importance to individual steps within the production chain because the subject has been neither extensively investigated nor definitely detailed (Allione et al., 2011; Bosco et al., 2011).

The focus will be on analysing the steps of production from an environmental point of view. In particular, the following steps of the project have been essential in defining the proposed themes:

1) the decision to create a taxonomy (bronze, silver, and gold);

2) research methodologies to establish thresholds and assign scores (Life Cycle Assessment (LCA) has especially been chosen and studied in this framework);

3) application of the LCA methodology to a case study of a chocolate-producing small- and mediumsized enterprise (SME), and testing of the same. 


\section{Experimental Section}

For the first point, a taxonomy must be defined to evaluate the importance of the various criteria within a framework to assess the sustainability performance of industry (Harik et al., 2015 and Labuschange et al., 2005). In other cases, instead, it is used to classify data and build qualitative indices (López-Ridaura et al., 2002). To evaluate production from an environmental standpoint, the study group decided to build a taxonomy with 'gold', 'silver', and 'bronze' levels to:

- grade the achievement of the index in subsequent steps, if necessary;

- differentiate individual environmental efforts based on the different skills and competences of companies.

The second step concerning the choice of methodologies turned out to be the most complex. The index framework has to make use of accurate and clear models that are also simple for consumers to understand. Especially in the food industry, where many labels are born, certain methods such as LCA have spread more than others to evaluate the environmental impact of products (Mogensen et al., 2009; Wognum et al., 2011). It is a known fact that the LCA method has proven to be the only complete tool that highlights the most polluting aspects of a life cycle and their order of importance. LCA is an objective evaluation procedure that is used to study the energy and environmental impacts related to a product, process, or activity. Traditional methods prefer to analyse single elements of production processes, while LCA considers the overall system ('from cradle to grave'), in which all transformation phases are taken into account because they participate in the implementation of the production process. Standard LCA phases (according to ISO 14040-44:2006 standards) include: 1) goal definition and scope; 2) Life Cycle Inventory analysis (LCI); 3) Life Cycle Impact assessment (LCIA); 4) life-cycle interpretation and improvement.

The principal scope of this study was to test the possible use of a method to establish when certain levels are achieved, after which the company acquires the index. The method that was used for the gold level was defined using LCA, however two other methodologies had to be chosen along with it, one for the silver level and one for the bronze level, which are mentioned to complete the rationale. The options were few, and were constrained by the need for them to be sufficiently well known and not too difficult to apply.

Best Available Techniques (BAT) were identified among other methodologies that can be adopted to evaluate the production cycle in terms of environment. They have been introduced through the Directive on integrated pollution prevention and control, now, Directive IED 2010/75/EU of the European Parliament and of the Council of 24 November 2010 on Industrial Emissions (integrated pollution prevention and control). This regulation introduces a procedure for authorising activities characterised by a high pollution potential, and sets minimum requirements for all permits in terms of pollutants released 
to ensure a high degree of environmental protection. BAT designates the most effective and advanced stage in the development of activities and their operating methods that allows efficient environmental improvement, compared with better methods from an economic and technological point of view. BAT explain how to discern the most important impact of each production process according to the law. The analysis of a production cycle has been considered to draw up the 'silver' standard checklist.

The last tool used to create an evaluation framework is preliminary environmental analysis based on the environmental management system. Preliminary environmental analysis is an essential step in the environmental management of an activity, and allows the extensive analysis of environmental aspects that interfere with the production process and the evaluation of their impact. It constitutes the first phase in the creation of an environmental management system that could be ISO 14001 certified or guaranteed by registration with the EMAS (Brida, 2002; Beltramo and Quaglino, 2002; Luciani et al., 2001). It has been employed to qualify companies for the index because it allows a complete analysis that takes into account all processes involved in order to make either improvements or changes, depending on the goals of the company. Said improvements can lead to higher grades of evaluation.

It is easier to obtain the last two standards (silver and bronze) than the first one, following the intentional taxonomy of the index. After the reference methodologies were established, it was necessary to understand how to use them to establish thresholds. In fact, 'One indicator does not say anything about sustainability, unless a reference value such as thresholds is given to it' (Lancker et al., 2000). For the gold standard, which uses the LCA method, the analysis focuses on key environmental aspects. The first step entails studying an adequate number of production cycles in the same field that key environmental aspects and average threshold levels are based on. A company that obtained the index (gold standard) would have to implement LCA analysis and make a comparison with the established threshold. The second degree of difficulty, according to BAT, comes from calculating BAT compliance, which is quantified by the questions elaborated and the scores assigned to each of them. By implementing the preliminary environmental analysis, the firm identifies the points to be improved, and may propose actions it can undertake for index evaluation.

During the project, the theoretical part designed by each research group was followed by practical experimentation in three case studies of the most representative regional products to which the index should be anchored. The chocolate production cycle was the first of these to be investigated.

The LCA study applied to the case of chocolate production mentioned below was significant to underscore the results and highlight problems. 


\subsection{Gold level with LCA in a chocolate firm}

The only studies available regarding chocolate analysis were related to areas that were so unlike the Italian context as to be unsuitable (Busser and Jungbluth, 2009; Ntiamoah and Afrane, 2008), and therefore it was difficult to use them as comparative parameters. LCA was applied to a chocolate company located in the province of Cuneo in Piedmont in order to highlight the strong and weak points of the production cycle from an environmental perspective (Vesce and Pairotti, 2014).

As mentioned, LCA is the best method for highlighting the environmental impact of production and to hypothesise improvement strategies (Andersson, 2000; Blengini and Busto, 2009; Borsacchi et al., 2004; Salomone and Ioppolo, 2012). This study applies the Impact 2002+ method for the LCA phase (Joillet et al., 2003). This method allows us to calculate middle- and end-point categories, and includes 14 impact categories measured in equivalent substances, and four damage categories:

- Human Health, measured in DALY (disability adjusted life year);

- Ecosystem Quality, measured in PDF $\cdot \mathrm{m}^{2} \cdot \mathrm{yr}$ (potentially disappeared fraction);

- Climate Change, measured in $\mathrm{kg}$ of $\mathrm{CO}_{2}$ equivalent in air, which is derived from the global warming impact category;

- Resources, measured in MJ, which come from non-renewable energy and mineral extraction.

\subsubsection{The definition of goal and scope, system boundaries, inventory}

The aim of this analysis is to calculate the environmental impact associated with the life cycle of the chocolate producer Venchi S.p.A., since it was decided to carry out LCA only on the transformation phase (only present in the region of investigation), although it is known that the agricultural phase, despite not being always controllable by European producers, has the greatest environmental impact. Indeed, to date, few manufacturers in Piedmont start from the cocoa bean, and many instead begin the cycle using a semi-finished product from Europe. This aspect, which is no longer followed by niche manufacturers, does not allow for accurate control of the raw material used in the production of semi-finished products, and can have a lesser influence on the cultivation techniques of cocoa farmers.

The life-cycle system boundaries thus range from the arrival of raw materials (cocoa and cocoa mass) at the company, including the transport phase, to the packaging of chocolates made in a master batch. Cocoa cultivation and the steps implemented to obtain the raw material are excluded, and so is the production of other ingredients (for reasons of formula confidentiality), the packaging of raw materials, the distribution phase, and finally the use and end of life of the product.

The functional unit chosen is $1 \mathrm{~kg}$ of chocolate divided into $3 \mathrm{~g}$ chocolates, individually wrapped and packaged in polypropylene, aluminium, and duplex film (an outer film of polypropylene bi-oriented lacquered acrylic and an inner one of PVDC and polypropylene). Data collected during the inventory 
carried out in the company, exploiting secondary data from databases, refer to the functional unit (Cerutti et al., 2011; Rebitzer et al., 2004).

The LCA focuses on chocolate production, from the cocoa mass (obtained by mixing two cocoa masses) combined with two types of dark chocolate. The analysis begins from the moment the raw materials enter the plant and continues to the weighing and mixing phases of the ingredients. Primary data is thus defined because it is directly collected at the analysed production site, in this case Venchi S.p.A.

For each material and each plant area (and also for finished product packaging), we considered the following items, namely the production of materials, processing, transport from supplier to company, and end-of-life scenario.

Figure 1. Flowchart of fondant chocolate production and system boundaries of the LCA study (the broken line shows excluded phases)

Table 1. Description of chocolate production phases at Venchi.

The input allocation (Bevilacqua et al., 2007) is performed with mass criteria.

The inclusions in the life-cycle system boundaries are: all inputs (such as water, energy, packaging materials) and outputs (emissions and waste) of the operations of manufacturing the product as well as the equipment needed for each manufacturing phase according to its service life.

The calculation data of energy consumption was carried out using the $\mathrm{kW}$ power of each piece of equipment and the respective operating time (hours). The distribution of gross and net weight $(\mathrm{kg})$ proportionate to the functional unit considered $(1 \mathrm{~kg})$ was used for the calculation data of the packaging materials.

\subsubsection{Impact assessments}

The main environmental aspects highlighted by LCA help to create the threshold reference values required to obtain the Index. The impact analysis (Pennington et al., 2004; Yan et al., 2011) allows us to classify the data gathered during the inventory into impact categories, and to perform characterisation, that is, calculate a single environmental impact indicator.

Table 2. Characterisation analysis of the chocolate cycle of production [UF:1 kg]. 
The total damage is expressed in eco-points or points $(\mathrm{Pt})$, which are obtained through a comparative analysis of the phases and categories that might cause more or less environmental damage. Figure 2, below, shows this weighting for chocolate production.

Figure 2. Diagram of the evaluation analysis of a single score (Pt) for damage categories [UF:1 kg]

The more significant issues arise from the mixing, potting, and grinding manufacturing phases. They mainly affect the depletion of resources and climate change categories, while the supply of raw materials phase causes greater damage to human health and the quality of the ecosystem.

The analysis of a single process contribution to the total environmental impact for each manufacturing phase shows that the most significant processes are as follows:

- electricity consumption of chocolate manufacturing phase;

- transport of raw materials supply;

- production of aluminium (80\% recycled) used as one of the primary polylaminate packaging materials (in the enveloping phase);

- PVDC used in secondary packaging;

- the process of plastic moulding used in various components;

- plastic for primary packaging;

- cardboard of tertiary packaging.

The following chart (Figure 3) highlights the main resources and emissions arising from the result of the LCIA.

Figure 3. Division by percentage of damage points $(\mathrm{Pt})$ for emitted substances and those extracted in all processes [FU:1 kg]

As shown in Figure 3, the $\mathrm{CO}_{2}$ emissions into the air and the depletion of natural gas resources are the most significant issues, mainly due to the energy consumption of the manufacturing phases of chocolate.

\subsubsection{Impact assessment on the Piedmont region}

Considering the Piedmont region, it has been noted that many producers of chocolate start from cocoa mass. To quantify the environmental impact in Piedmont and to identify appropriate ways to help reduce it, only the part of the production cycle that actually affects Piedmont has been considered, that is, from mixing the ingredients to the finished product. 
The solutions identified and now implemented are achievable by addressing a scenario mainly consisting of small producers (although there are big producers). A survey conducted in April 2011 by the Turin Chamber of Commerce found that out of a total of 105 activities present in the region, more than $77 \%$ had fewer than 25 employees.

Since the proposed improvement actions based on LCA are used to obtain a product index that must be disseminated, the necessary conditions to reach this result must be created. For example, asking the suppliers for a substantial change in the search for raw materials with special characteristics does not always seem feasible for an SME. However, within the project we are evaluating the hypothesis of producers effectively considering purchasing certified cocoa, as there are diverging opinions on this point (Edwards et al., 2012).

Table 3, below, shows the results of the LCA sensitivity analysis, that is, analysis of characterisation, and the data obtained from the same analysis presented in Table 2, excluding the raw material transport phase.

Table 3. Characterisation analysis of the chocolate cycle of production without raw materials transport [UF:1 kg]

Figure 4. Diagram of the evaluation analysis of a single score $(\mathrm{Pt})$ for damage categories without raw materials transport [UF:1 kg]

The mixing, potting, and grinding phase also appears to have a considerable impact on the manufacturing life cycle, without considering the transport of raw materials to the company; indeed, it has a major impact on Resource Depletion, Climate Change, and Ecosystem Quality.

The analysis of single process contributions to the total environmental impact for each manufacturing phase in the sensitivity analysis shows that the most significant processes are as follows (in decreasing order):

- the electricity consumption of the manufacturing phase of the chocolate

- the production of aluminium (80\% recycled) used as material polylaminates in primary packaging;

- PVDC used in secondary packaging;

- the process of plastic moulding used in the various components;

- the plastic used in primary packaging;

- the cardboard of the tertiary packaging. 
Figure 5. Division by percentage of damage points $(\mathrm{Pt})$ for emitted substances and those extracted in all processes without raw materials transport [FU:1 kg]

Table 4. Comparison among damage evaluation data

Excluding the phase of supply of the raw material, there is a reduction in damage, in this case measuring 0.000528 points, or $25 \%$ of the previous data (0.000689).

Between inputs, the demand for electricity required to operate the machinery is certainly the main factor of environmental impact in a process that does not require high quantities of water or raw materials.

As mentioned, the Italian energy mix does not help in terms of environmental impact. At present, the only way to make improvements in terms of climate change and resource consumption is to reduce consumption or to source from renewable energy.

Venchi S.p.A. now covers 5\% of its energy needs through the installation of solar panels on the roof of the plant, and the company could indeed already be listed in the Poliedro Index with regard to the environmental aspect of transformation.

\section{Results and Discussion}

The goals stated in the introduction practically lead to the definition of two factors that are deemed to be most complicated, namely the definition of certain environmental assessment methods applied to the production phase to create thresholds for the acquisition of the Index, and testing the use of at least one method to verify its effectiveness and to detect its problems in a practical case.

The first point is based on a theoretical study of the use of various analysis tools. In fact, the LCA method in the food sector, as observed in some studies (Mogensen et al., 2009), can be used for at least four different purposes. The first is the primary purpose of defining the most significant environmental impacts in an entire production cycle, from cradle to grave, in order to guide improvement. The second point lies in highlighting the effects of the changes, avoiding the problem of shifting the impact from one production phase to another. The third point consists of comparing the impact of a company with that of others operating in the same sector, considering a series of parameters, such as carbon footprint, soil acidification, etc. It is obvious that this can only be implemented with the same initial hypotheses. The fourth goal for which the LCA is used consists of obtaining a product label, for example those used for Ecolabel criteria, or an environmental statement, such as an EPD (Wognum et al., 2011). Both these tools envisage the use of the LCA as a scientific method that provides certain values which are used by the two systems in a diversified manner. The Ecolabel criteria help suppliers to be selective and, hence, the 
results of the LCA become the discriminating value to access the list of companies from which the brands most suitable to be given the label will be chosen. An EPD is not a label, as it is merely a 'statement' of environmental results.

The scope that is closest to the use of the LCA in this study is the third one, which makes use of LCA as a comparative factor for certain parameters.

As regards the second aspect, the most practical method is of the tool's application to a production framework through which the method can be tested. The study attempted to test the possibility of making LCA a tool that can be used at all investigation levels, a tool that is much 'closer' to the production frameworks than it has been in recent years.

The application of LCA to the case of chocolate has brought to light a series of problems that have always been associated with this method, namely the lack of data and the need to adopt the same initial hypotheses to carry out the comparative study.

In Italy, there are no such studies in the chocolate sector. The only study on chocolate production, as mentioned, refers to Ghana (Ntiamoah and Afrane, 2008), and has been recently continued with the addition of some aspects, especially concerning consumption in Europe and the comparison between the various types of chocolate, in a presentation made during the $24^{\text {th }}$ Annual Meeting of SETAC Europe (Jungbluth, and Konig, 2014).

The problem especially arose when very 'local' situations had to be compared. This study only required a comparison of the production phase of chocolate to assign a positive score to companies that planned on acquiring the index through the LCA-based method. The issue of using the same functional unit, which was a premise for the analysis, can also be solved. However, establishing the limits of the analysis was especially a problem.

If the necessity should arise, with the same conditions, to assess the lesser environmental impact of companies that, given their location, do not grow cocoa but only process it, a gate-to-gate analysis will have to be performed, despite being scientifically less effective. However, if the companies that have to be compared or, on the other hand, must form the reference sample, start from different processing points, the problem will arise once again.

The project started by analysing the cocoa mass (semi-processed), as this is used by most companies that are based in Piedmont, though many companies, especially those which possess expert craftsmanship, have included the cocoa bean in their processing phase in recent years. Then, the issue of including transport in the impact calculation was considered. It is evident that the phase of the whole life cycle that has the most impact is the farming phase (Jungbluth and Konig, 2014). However, the assessments made are used to qualify companies that belong to the same territorial framework, far from the farming phases, unless the decision is made that, in order to acquire the index, companies must 
purchase their supplies from farms that somehow certify their environmental interest during the cultivation phase of the raw material. From a certain standpoint, all the companies 'start' from the same situation, and can provide evidence of their respect for the environment for all phases over which they have some control. As regards the transport of semi-finished products to the factory for subsequent processing, the decision was made to perform two analyses that first included it, and then excluded it, as indicated by the analysis mentioned in the previous paragraph. The first process, in terms of contribution towards environmental damage, results from the composition of the Italian energy mix. The use of technologies with lower energy consumption or resorting to renewable sources (the path that was actually followed by the analysed company) might lead to an improvement both in terms of expenses and consumption. If transportation is included in the analysis, the impact resulting from this process will follow soon after. This might suggest that internal product processing to arrive at the semi-processed product or getting supplies from companies that are situated at a closer distance should be assessed (currently the semi-finished product is supplied by a leading European multinational).

Even packaging, as considered in the analysed case, is one of the items that generated an impact. The choice of less invasive and equally effective packaging might reduce the impact of the observed process. Moreover, this theme has been extensively discussed in the literature regarding the comparison of feasible alternative choices (Büsser and Jungbluth, 2009).

\section{Conclusions}

Considering the analysis conducted and the experience of applying the LCA method to corporate cases (Pairotti et al., 2013), we can say that the LCA can be used to underpin a comparative method for obtaining an index as long as there are clear premises for terms such as the limits of the system and the functional unit. The first and now consolidated deficiency that surfaced concerns primary data and the lack of national databases. If mean pollution data have to be found to define the limit thresholds, it will be necessary to consider a simplified implementation of LCA, especially for SMEs. Even the presence of sensors that monitor the progress of the most important environmental variables could be an advantage in terms of data collection and procedural simplification, and for performance control on the part of the company (Cantore et al., 2013). The above could contribute towards improving the environmental situation and also towards increasing the related economic efficiency.

Large-scale dissemination of the rigorous LCA method through paradigms can be the method for defining an index which, studied in advance to facilitate application, could lead to efficiency rates ranging beyond the acquisition of said qualification index, in turn forming competitive advantages for the companies that implement them. 


\section{References and Notes}

- Allione, C., De Giorgi, C., Lerma B. and Petruccelli L. (2011) "Sustainable food packaging: A case study of chocolate products" in LCM 2011 - Towards Life Cycle Sustainability, 5th International Conference on Life Cycle Management, Berlin, p. 12.

- Andersson, K. (2000) "LCA of food Products and Production Systems", International Journal of Life Cycle Assessment, vol. 5, pp. 239-248.

- Bedrrich, M., Svatava, J., Hák, T. (2012) "How to understand and measure environmental sustainability: indicators and targets", Ecological Indicators, vol. 17, pp. 4-13.

- Beltramo, R. and Quaglino, A. (2002) Linee guida per l'introduzione di sistemi di gestione ambientale nelle aziende vinicole, $1^{\text {st }}$ ed., Argograf, Asti,Italy.

- Bevilacqua, M., Braglia, M., Carmignani, G. and Zammori, F. (2007) "Life cycle assessment of pasta production in Italy", Journal of Food Quality, vol. 30, pp. 932-952.

- Blengini, G.A., Busto, M. (2009) "The Life Cycle of rice: LCA of alternative agri-food chain management systems in Vercelli (Italy)", Journal of Environmental Management, vol. 90, pp. $1512-1522$.

- Borsacchi, L., Olivieri, G., Scotti, S., Neri, P., Tacconi, D. and Romani, A. (2004) "Analisi del ciclo di vita (LCA) e implementazione di un sistema integrato qualità - sicurezza - ambiente per la produzione di pasta biologica tipica”, in Risorse naturali e sviluppo economico-sociale, XXI Congresso Nazionale di Merceologia Foggia, Italia, by Spada, V., Tricase, C., VIP Edizioni, Bari, Italy, 2005.

- Bosco, S., Di Bene, C., Galli, M., Remorini, D., Massai, R. and Bonari, E. (2011) "Greenhouse gas emissions in the agricultural phase of wine production in the Maremma rural district in Tuscany, Italy", Italian Journal of Agronomy, vol.6, pp. 93-100

- Brida, L. (2002) Linee guida sui sistemi di gestione ambientale per cantine e vini, Agenzia provinciale per la protezione dell'ambiente e la tutela del lavoro, Provincia Autonoma di Bolzano, Bolzano [online] http://www.provincia.bz.it.

- Büsser, S. and Jungbluth, N. (2009) "LCA of Chocolate Packed in Aluminium Foil Based Packaging”, ESU-services Ltd. Uster, Switzerland, 2009. Commissioned by German Aluminium Association (GDA) in cooperation with European Aluminium Foil Association (EAFA), Düsseldorf, Germany. 
- Cantore, P., Pairotti, M.B., Vesce, E. and Beltramo, R. (2013) "Sostenibilità ambientale della fase di trasformazione nelle piccole imprese e lo strumento Scatol $8^{\circledR ”}$, Indice Poliedro, $1^{\text {st }}$ ed., Università di Scienze Gastronomiche, Pollenzo, Bra, Italy, pp. 90-97.

- Cerutti, A.K., Galizia, D., Bruun, S., Mellano, M.G., Beccaro, G. and Bounous, G. (2011) “Assessing Environmental Sustainability of Different Apple Supply Chains in Northern Italy", Towards Life Cycle Sustainability Management, Finkbeiner M. Ed., Springer Science+Business Media B.V., Heidelberg, Germany, pp. 341- 348.

- Coultate, T.P. (2005) La chimica degli alimenti, $5^{\text {st }}$ ed., Zanichelli, Bologna, Italy.

- Edwards, D.P., Laurence, S.G. (2012) “Green Labelling, sustainability and expansion of tropical agriculture: critical issue for certification scheme", Biological conservation, vol. 151, n. 1, pp. 6064.

- GEDnet - Global Environmental Declarations Network [online] http://www.gednet.org (accessed on $04 / 07 / 2014)$.

- Engels, S. V., Hansmann, R., Scholz, R. W. (2010) "Toward a Sustainability Label for Food Products: An Analysis of Experts' and Consumers' Perspective", Ecology of Food and Nutrition, vol. 49 , pp. 30-60

- Halberg, N., Van der Werf, H.M.G., Basset-Mens, C., Dalgaard, R. and De Boer I. (2005) "Environmental assessment tools for the evaluation and improvement of European livestock production system", Livestock Production Science, vol. 96, pp. 33-50.

- Harik R., EL Hachem W., Medini K., Bernard A. (2015) “Towards a holistic sustainability index for measuring sustainability of manufacturing companies", International Journal of Production Research, vol. 53, n. 13, pp. 4117-4139.

- Herva, M., Franco, A., Carrasco, E.F., Roca, E. (2011) "Review of corporate environmental indicators", Journal of Cleaner Production, vol.19, pp. 1687 - 1699.

- Huysman S., Sala S., Mancini L., Ardente F., Alvarenga R., De Meester S., Mathieux F., Dewulf J. (2015) "Toward a systematized frame work for re source efficiency indicators", Resources, Conservation and Recycling, vol. 95, pp. 68-76.

- Jolliet, O., Margini, M., Charles, R., Humbert, S., Payet, J., Rebitzer, G. and Rosenbaum, R. (2003) “IMPACT 2002+: A New Life Cycle Impact Assessment Methodology", International Journal of Life Cycle Assessment, vol. 8, pp. 324-330.

- Jungbluth, N. and Konig A. (2014) "A Life Cycle Assessment of Swiss Chocolate” Presented at SETAC Europe $24^{\text {th }}$ annual Meeting, 15th May 2014. Bale, Croatia 
- Labuschagne, C., Brent, A.C., van Erck, R. P. G. (2005) Assessing the sustainability performances of industries, Journal of Cleaner Production, vol. 13, pp. 373 - 385.

- Lancker, E. and Nijkamp, P. (2000) “A policy scenario analysis of sustainable agricultural development options: a case study for Nepal”, Impact Assessment and Project Appraisal, vol. 18, No.2, pp. 111-124.

- López-Ridaura, S., Masera, O. and Astier, M. (2002) "Evaluating the sustainability of complex socio-environmental systems. the MESMIS framework”, Ecological Indicators, vol. 2, pp. 135148.

- Luciani, R., Andriola, L. and Di Franco, N. (2001) Analisi ambientale iniziale per imprese di piccole dimensioni, ENEA, Roma.

- Mogensen, L., Hermansen, J.E., Halberg, N., Dalgaard, R., Vis, J.C. and Smith, B.G. (2009) "Life Cycle Assessment across the Food Supply Chain", in Cheryl, J., Baldwin (Ed.), IFT Press, Wiley-Blackwell, Sustainability in the Food Industry, pp. 115-144.

- Ness, B., Urbel-Piirsalu E., Anderberg, S. and Olsson, L. (2007) "Categorising tools for sustainability assessment”, Ecological Economics, vol. 60, pp. 498-508.

- Ntiamoah, A. and Afrane G. (2008) "Environmental impacts of cocoa production and processing in Ghana: life cycle assessment approach", Journal of Cleaner Production, vol. 16, pp. 17351740.

- Olsthoorn, X., Tyteca, D., Wehrmeyer, W. and Wagner M. (2001) "Environmental indicators for business: a review of the literature and standardisation methods", Journal of Cleaner Production, vol. 9, pp. 453-463.

- Pairotti, M.B., Vesce, E. and Beltramo, R. (2013) "Sostenibilità ambientale: la metodologia della fase di trasformazione", in Indice Poliedro, $1^{\text {st }}$ ed., Università di Scienze Gastronomiche, Pollenzo, Bra, Italy, pp. 74-81.

- Pennington, D.W., Potting, J., Finnveden, G., Lindeijer, E., Joillet, O., Rydeberg, T. and Rebitzer, G. (2004) “ Life Cycle assessment Part 2: current impact assessment practise”, Environment International, vol. 30, pp.721-739.

- Rebitzer, G., Ekvall, T., Frischknecht, R., Hunkeler, D., Norris, G., Rydberg, T., Schmidt, W.P., Suh, S., Weidema, B.P. and Pennington, D.W. (2004) "Life cycle assessment Part 1: Framework, goal, scope definition, inventory analysis and application", Environment International, vol. 30, pp. 701-720. 
- Salomone, R. and Ioppolo, G. (2012) "Environmental impacts of olive oil production: a Life Cycle Assessment case study in the Province of Messina (Sicily)", Journal of Cleaner Production, vol. 28, pp. 88-100.

- Van der Werf, H.M.G. and Petit, J. (2002) "Evaluation of the environmental impact of agriculture at the farm level: a comparison and analysis of 12 indicator-based methods", Agriculture Ecosystem\& Environment, vol. 93, pp. 131-145.

- Vesce, E. and Pairotti, MB (2014) Una proposta per la costruzione di un indice multidisciplinare per la valorizzazione dei prodotti agroalimentari: il progetto Poliedro e la parte ambientale, in Materiali e tecnologie ecosostenibili come nuova opportunità, $1^{\text {st }}$ ed., Aracne Editrice, Roma, pp. 195-209.

- Wognum, P.M., Bremmers, H., Trienekens, J.H., Van der Vorst Jack G.A.J. and Bloemhof J.M. (2011) "Systems for sustainability and transparency of food supply chains - Current status and challenges", Advanced Engineering Informatics, vol. 25, pp. 65-76.

- Yan, M., Humphreys, J. and Holden, N. (2011) "An evaluation of life cycle assessment of European milk production”, Journal of Environmental Management, vol.92, pp. 372-379.

Notes:

(1) The environmental index is part of Poliedro Index, financed by Regione Piemonte in the "Human and Social Sciences" project, and it is a product label that can easily be graphically represented, and which converges various aspects of sustainability, environmental, economic and social one, in a single index. 
Figure 1. Flowchart of fondant chocolate production and system boundaries of the LCA study (the broken line shows excluded phases)

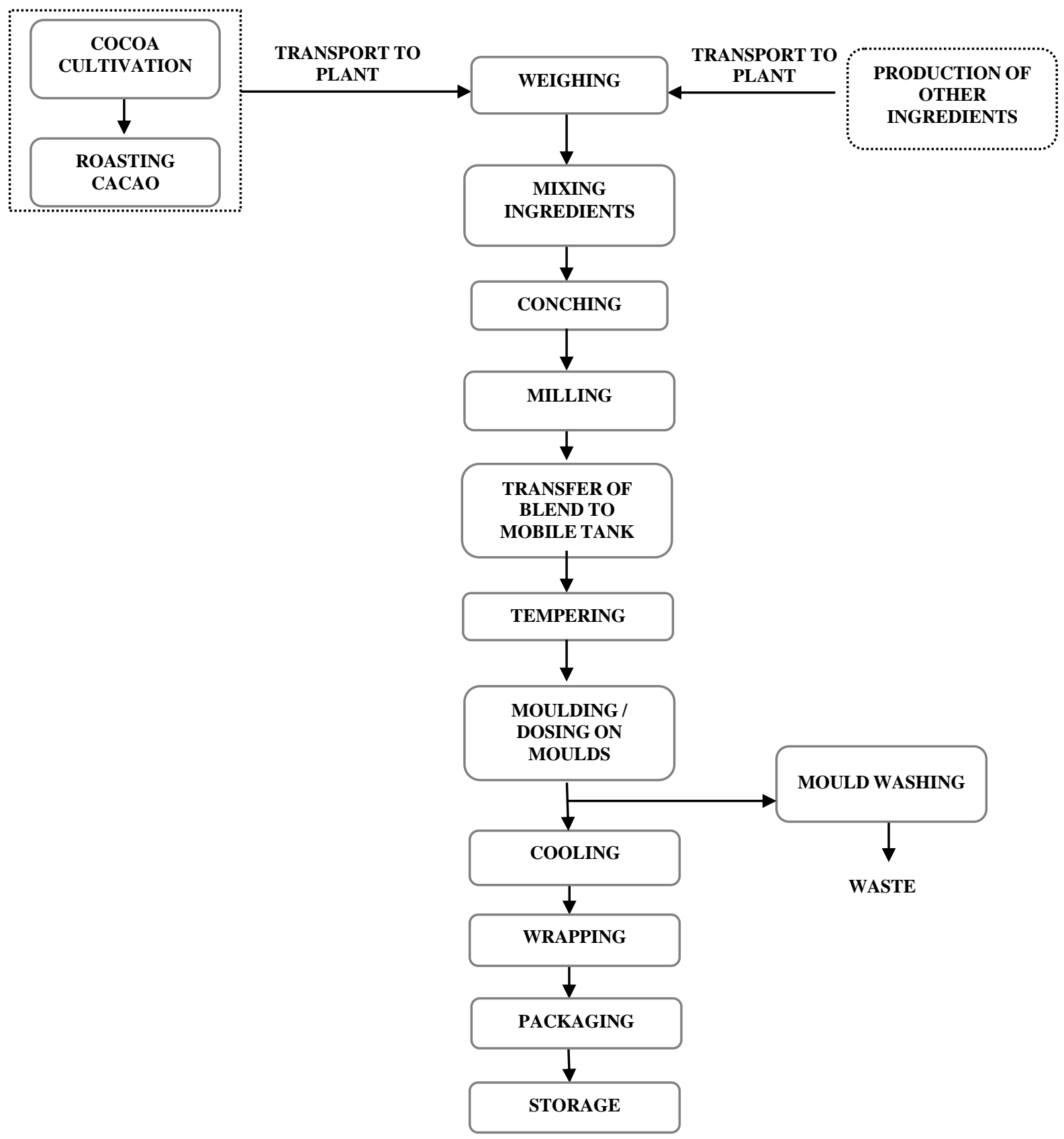


Table 1. Description of chocolate production phases at Venchi.

\begin{tabular}{|c|c|}
\hline Main Phase & Description \\
\hline $\begin{array}{l}\text { Supplying of } \\
\text { raw materials }\end{array}$ & $\begin{array}{l}\text { This phase was analysed by taking into account the distances } \\
\text { from raw material manufacturing plant to the company plant } \\
\text { (estimated as an average of } 1,000 \mathrm{~km} \text { ) and the vehicles used to } \\
\text { transport them to the company }(\mathrm{kg} / \mathrm{km} \text { ). }\end{array}$ \\
\hline Mixing/potting/grinding & $\begin{array}{l}\text { This step consists of mixing the ingredients according to the } \\
\text { product recipe, and then developing the typical aroma through } \\
\text { long fluid chocolate homogenisation, during which the mass is } \\
\text { churned at a controlled temperature in the appropriate mixers } \\
\text { (conches). } \\
\text { The process finally yields a soft velvety paste with no traces of } \\
\text { moisture or acidity (Coultate, 2005). }\end{array}$ \\
\hline $\begin{array}{l}\text { Transferring mixture } \\
\text { using a tank trolley }\end{array}$ & - \\
\hline $\begin{array}{l}\text { Tempering/moulding/ } \\
\text { cooling }\end{array}$ & $\begin{array}{l}\text { During this phase, the cocoa butter crystallises into a stable form } \\
\text { (Coultate, 2005); then fluid chocolate is poured into moulds, } \\
\text { which are subjected to vibration in order to eliminate air bubbles. }\end{array}$ \\
\hline Wash moulds & - \\
\hline Wrapping & This phase consists of the individual chocolates being wrapped. \\
\hline Packaging & $\begin{array}{l}\text { During this phase, the chocolates are placed in duplex film bags } \\
\text { and then in cardboard boxes (which may contain four bags of } \\
\text { chocolates, each weighing } 1 \mathrm{~kg} \text { ). }\end{array}$ \\
\hline
\end{tabular}


Table 2. Characterisation analysis of the chocolate cycle of production [UF:1 kg].

\begin{tabular}{|l|l|l|}
\hline Category & Indicator & Most relevant phase \\
\hline Global warming & $1.91 \mathrm{~kg} \mathrm{CO}$ equivalent & Mixing/potting/grinding \\
\hline Ozone depletion & $2.34 \mathrm{E}-7 \mathrm{~kg} \mathrm{CFC}-11$ equivalents & Mixing/potting/grinding \\
\hline Terrestrial ecotoxicity & $4.72 \mathrm{E}+01 \mathrm{~kg} \mathrm{TEG}$ * soil & Supplying of raw materials \\
\hline Aquatic ecotoxicity & $2.96 \mathrm{E}+02 \mathrm{TEG}$ water & Supplying of raw materials \\
\hline Non-renewable energy & $3.57 \mathrm{E}+01 \mathrm{MJ}$ primary & Mixing/potting/grinding \\
\hline
\end{tabular}

*Triethylene Glycol

Figure 2. Diagram of the evaluation analysis of a single score (Pt) for damage categories [UF:1 kg]

Weighting $(\mathrm{Pt})$

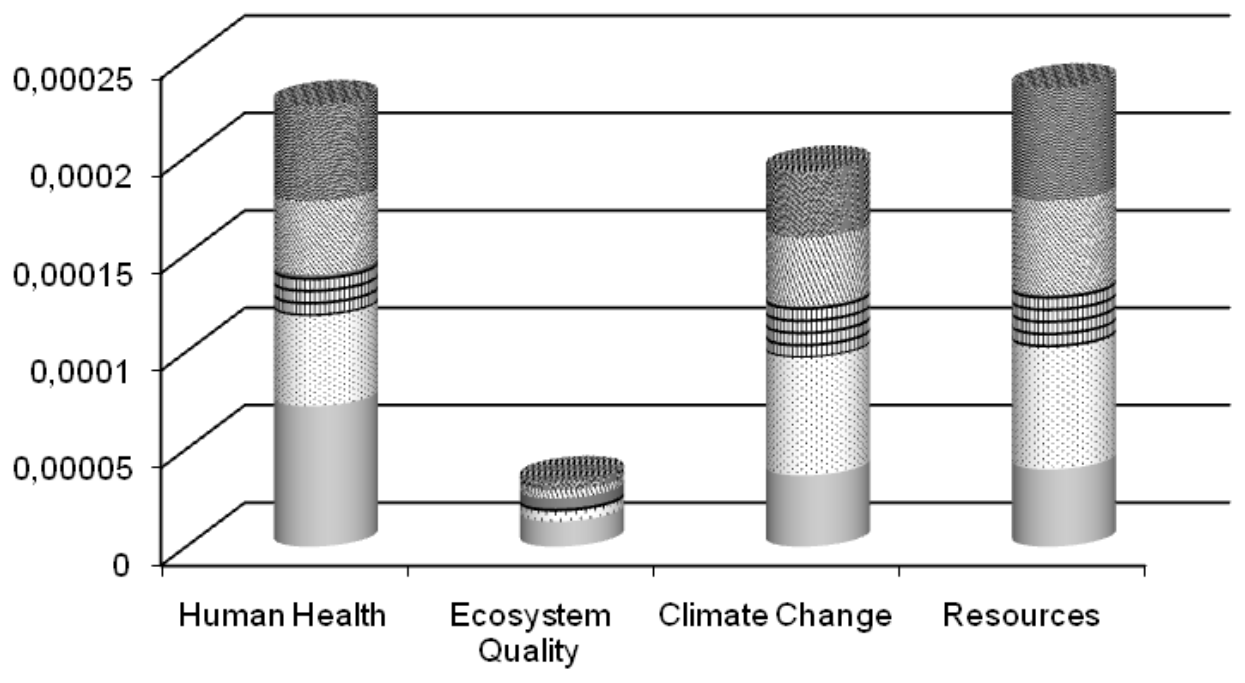

Packaging

NW Wrapping

- Wasghing

ÆTempering

$=\mathrm{T}$ ank

: Mixing/Potting/Grinding

- Supplying of raw material 
Figure 3. Division by percentage of damage points $(\mathrm{Pt})$ for emitted substances and those extracted in all processes [FU:1 kg]

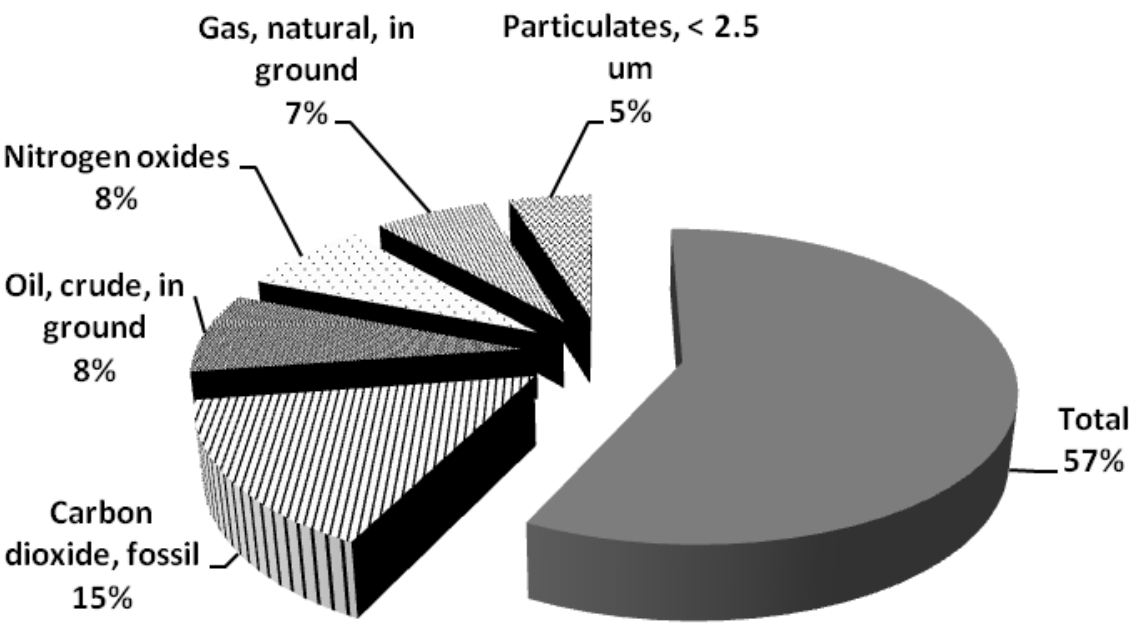


Table 3. Characterisation analysis of the chocolate cycle of production without raw materials transport [UF:1 kg]

\begin{tabular}{|l|l|l|}
\hline Category & Indicator & Most relevant phase \\
\hline Global warming & $1.55 \mathrm{~kg} \mathrm{CO}$ equivalents & Mixing/potting/grinding \\
\hline Ozone depletion & $1.85 \mathrm{E}-7 \mathrm{~kg} \mathrm{CFC}-11$ equivalents & Mixing/potting/grinding \\
\hline Terrestrial ecotoxicity & $2.86 \mathrm{E}+01 \mathrm{~kg} \mathrm{TEG} *$ soil & Wash moulds \\
\hline Aquatic ecotoxicity & $1.52 \mathrm{E}+02 \mathrm{TEG}$ water & Wash moulds \\
\hline Non-renewable energy & $2.96 \mathrm{E}+01 \mathrm{MJ}$ primary & Mixing/potting/grinding \\
\hline
\end{tabular}

* Triethylene Glycol

Figure 4. Diagram of the evaluation analysis of a single score $(\mathrm{Pt})$ for damage categories without raw materials transport [UF: $1 \mathrm{~kg}]$

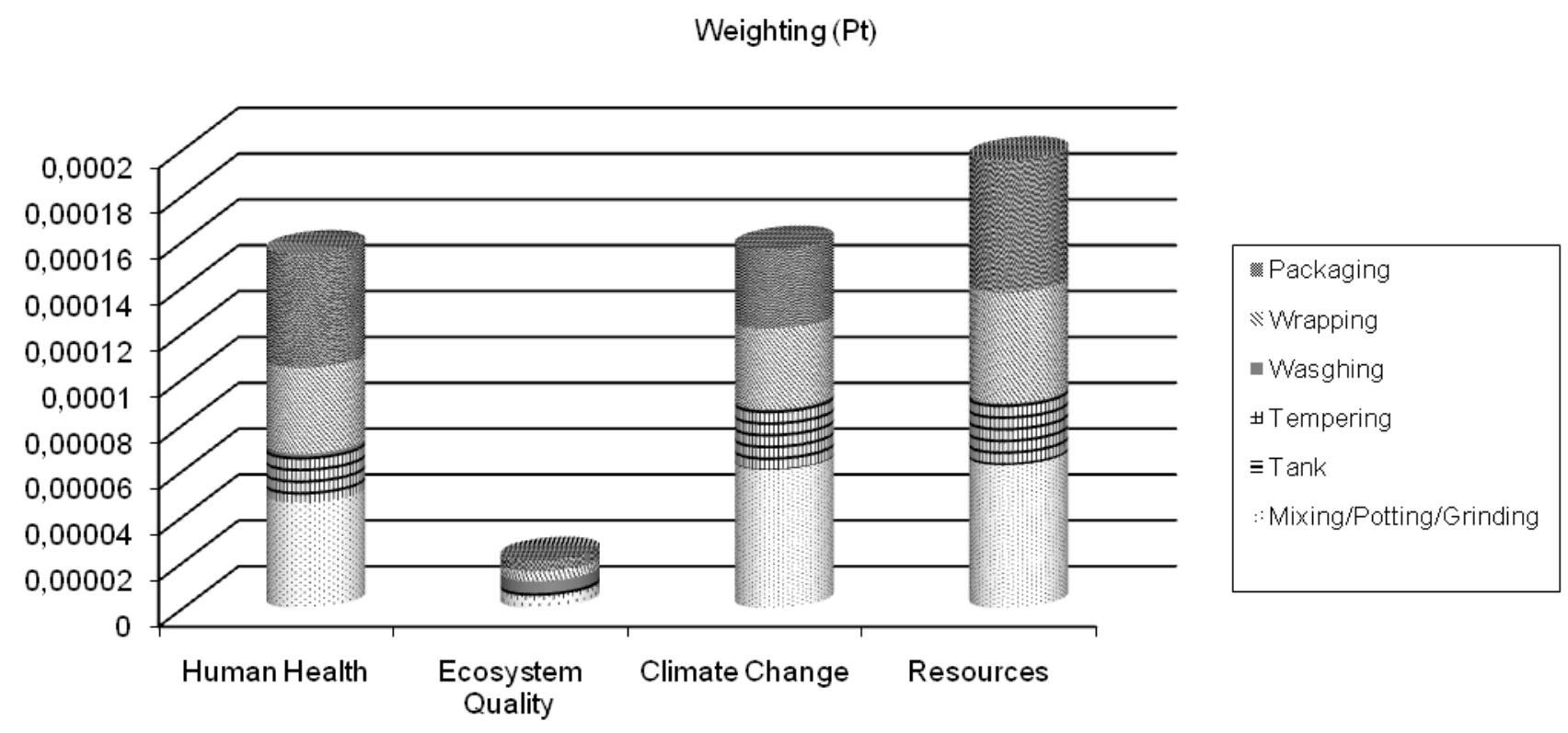


Figure 5. Division by percentage of damage points $(\mathrm{Pt})$ for emitted substances and those extracted in all processes without raw materials transport [FU:1 kg]

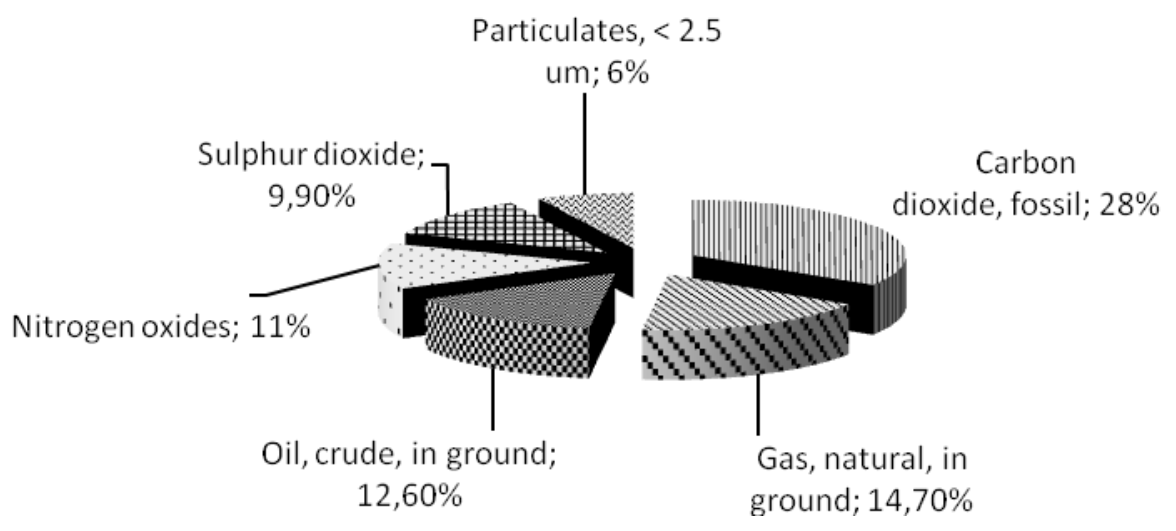

Table 4. Comparison among damage evaluation data

\begin{tabular}{|l|l|l|l|}
\hline Damage category & Unit & Chocolate production & $\begin{array}{l}\text { Chocolate production without } \\
\text { raw material transport }\end{array}$ \\
\hline Total & $\mathrm{Pt}$ & 0.000689 & 0.000528 \\
\hline Human Health & $\mathrm{Pt}$ & 0.000227 & 0.000155 \\
\hline Ecosystem Quality & $\mathrm{Pt}$ & $3.37 \mathrm{E}-05$ & $2.09 \mathrm{E}-05$ \\
\hline Climate Change & $\mathrm{Pt}$ & 0.000193 & 0.000157 \\
\hline Resources & $\mathrm{Pt}$ & 0.000235 & 0.000196 \\
\hline
\end{tabular}

